\title{
RESÍDUOS DE AGROTÓXICOS EM ALIMENTOS DE ORIGEM VEGETAL: REVISÃO
}

FLÁVIA REGINA PASSOS * MARCELO RODRIGUES DOS REIS **

\begin{abstract}
A presente revisão de literatura apresenta discussões provenientes de pesquisas sobre resíduos de agrotóxicos em alimentos de origem vegetal, com enfoque na determinação dos Limites Máximos de Resíduos (LMR) desses produtos em frutas e hortaliças. Foram abordados também o Programa de Análise de Resíduos de Agrotóxicos em Alimentos (PARA) e o Plano Nacional de Controle de Resíduos e Contaminantes de Produtos de Origem Vegetal (PNCRC/Vegetal) criados pelo Ministério de Agricultura, Pecuária e Abastecimento (MAPA). Concluiu-se que o uso seguro de agrotóxicos, objetivo de padrões e regulamentos, somente poderá ser alcançado mediante implementação efetiva de monitoramento periódico e consciente. A utilização das Boas Práticas Agrícolas (BPA), a certificação e a punição com multas podem contribuir para a diminuição da exposição do consumidor e do aplicador a essas substâncias tóxicas, responsáveis por sérias doenças, bem como minimizar seus efeitos adversos ao ecossistema.
\end{abstract}

PALAVRAS-CHAVE: FRUTAS E HORTALIÇAS; MONITORAMENTO; LIMITE MÁXIMO DE RESÍDUOS; RESÍDUOS DE AGROTÓXICOS.

* Mestranda em Agronomia (Produção Vegetal), Instituto de Ciências Agrárias, Universidade Federal de Viçosa Campus de Rio Paranaíba, Rio Paranaíba, MG (e-mail: flaviapassos1@yahoo.com.br).

** Doutor em Fitotecnia (Produção Vegetal), Professor, Instituto de Ciências Agrárias, Universidade Federal de Viçosa Campus de Rio Paranaíba, Rio Paranaíba, MG (e-mail: marceloreis@ufv.br). 


\section{INTRODUÇÃO}

O crescimento da população mundial e, consequentemente, o aumento da demanda por alimentos têm impulsionado o desenvolvimento de sistemas agrícolas cada vez mais eficientes (SHARMA et al., 2010). O uso de agrotóxicos tem sido a principal estratégia de controle e prevenção de pragas durante o cultivo e após a colheita, melhorando a produtividade e a qualidade da produção agrícola (GONZÁLEZ-RODRÍGUEZ et al., 2008). Sem a sua utilização podem ocorrer perdas significativas dos produtos agrícolas, aumento de doenças infecciosas e devastação de habitats por pragas invasoras (RICE et al., 2007).

Mais de 800 compostos, pertencentes a cerca de 100 classes químicas, estão registrados como ingredientes ativos de agrotóxicos comercializados no mundo (BOTITSI, ECONOMOU e TSIPI, 2007). Os agrotóxicos abrangem inseticidas, fungicidas, herbicidas, acaricidas, nematicidas, substâncias destinadas para uso como reguladores de crescimento, feromônios, desfolhantes e protetores de sementes (BAKIRCI e HIŞIL, 2012; EL-SHAHAWI et al., 2010).

A utilização de agrotóxicos proporciona vários benefícios, mas sua aplicação inadequada pode resultar na acumulação desses produtos químicos na água, solos e sedimentos, com permanência nas culturas (GONZÁLEZ-RODRÍGUEZ, CANCHO-GRANDE e SIMAL-GÁNDARA, 2011; SRIVASTAVA et al., 2011; JARDIM, ANDRADE e QUEIROZ, 2009; BAI, ZHOU e WANG, 2006). Dessa forma, podem chegar aos seres humanos por meio da cadeia alimentar e ocasionar danos à saúde (KHALILI-ZANJANI et al., 2008). Muitos agrotóxicos, principalmente da classe dos organoclorados e organofosforados, tiveram seu uso proibido devido a alta toxicidade, atividade residual e grande poder bioacumulativo (GALLI et al., 2006).

O monitoramento de resíduos de agrotóxicos em alimentos de origem vegetal constitui ferramenta importante para assegurar o cumprimento de Boas Práticas Agrícolas (BPA) (BRASIL, 2011) em razão das frutas e hortaliças serem consumidas in natura e/ou processadas e ingeridas por pessoas de todas as idades (BAKIRCI e HIŞIL, 2012). A Agência Nacional de Vigilância Sanitária (ANVISA) criou, em 2003, o Programa de Análise de Resíduos de Agrotóxicos em Alimentos (PARA), visando disponibilizar diagnósticos das concentrações de resíduos desses produtos em alimentos através dos Limites Máximos de Resíduos (LMR) (BRASIL, 2011b).

Um terço dos alimentos consumidos cotidianamente pelos brasileiros está contaminado por agrotóxicos, segundo análises realizadas pelo PARA de amostras coletadas nas 26 Unidades Federativas do Brasil. O estado de São Paulo tem seu próprio Programa de Análise Fiscal de Alimentos, denominado Programa Paulista (BRASIL, 2011b).

De acordo com o Ministério da Agricultura, Pecuária e Abastecimento (MAPA), no ano de 2008 foram lançadas 674 mil toneladas de agrotóxicos no meio ambiente e, em 2011, esse índice pode ter alcançado 853 mil toneladas, incluindo produtos proibidos em outros países. Segundo Carneiro et al. (2012), o Brasil é o maior consumidor de agrotóxicos representando $19 \%$ do uso mundial.

Objetivou-se nesta revisão apresentar discussões centradas em pesquisas sobre os resíduos de agrotóxicos em alimentos de origem vegetal, com enfoque na determinação dos Limites Máximos de Resíduos (MR) desses produtos em frutas e hortaliças.

\section{LEGISLAÇÃO}

Os vários tipos de agrotóxicos podem provocar contaminações de alimentos em função da capacidade tóxica de seus componentes e das peculiaridades de cada produto. Porém, a contaminação de alimentos por esses agroquímicos pode ser minimizada por meio de regulamentação rigorosa e treinamento adequado dos aplicadores (COOPER e DOBSON, 2007). Os agrotóxicos somente podem ser utilizados se forem registrados em órgão federal competente, de acordo com as diretrizes e exigências dos órgãos responsáveis pelos setores da saúde, do meio ambiente e da agricultura (BRASIL, 2011b; 2010a; 2009b). 
O Decreto 4.074 , de 4 de janeiro de 2002, que regulamentou a Lei 7.802 sobre agrotóxicos e afins, de 11 de julho de 1989, estabelece as competências de registro de agrotóxicos no Brasil para três órgãos: Ministério da Saúde (MS); Ministério da Agricultura, Pecuária e Abastecimento (MAPA); e Ministério do Meio Ambiente (MMA). O MS, por meio da Agência Nacional de Vigilância Sanitária (ANVISA), é o responsável pela avaliação e classificação toxicológica dos produtos além de estabelecer seus LMR com o objetivo de manter a segurança alimentar do consumidor e a saúde do trabalhador rural. Coordenado pela ANVISA, o PARA foi implementado em conjunto com os órgãos de Vigilância Sanitária estaduais e municipais (BRASIL, 2011b).

No âmbito internacional, os LMR são determinados pelo Comitê para Resíduos de Pesticidas do Codex Alimentarius (CCPR), seguindo recomendações da Food and Agriculture Organization (FAO) e da Organização Mundial de Saúde (OMS). Os países que não dispõem de sistema organizado de registro de agrotóxico adotam os limites instituídos pelo Codex Alimentarius (BRASIL, 2011b).

Os LMR correspondem a maior concentração que o agrotóxico pode estar presente nos alimentos sem causar malefícios à saúde humana, sendo expressos em $\mathrm{mg} \mathrm{kg}^{-1}$ de alimento (COOPER e DOBSON, 2007). Esses limites são garantidos ao se aplicar a dose recomendada pelo fabricante utilizando o número correto de aplicações, devendo ser respeitado o intervalo de segurança entre a última aplicação e a colheita da cultura (SRIVASTAVA et al., 2011).

Várias leis foram aprovadas em diversos países, inclusive no Brasil, visando estabelecer os LMR em alimentos de origem vegetal (ŠKRBIC e PREDOJEVIC', 2008). Esses procedimentos, em geral, visam minimizar os riscos de intoxicação crônica ou aguda pela ingestão de alimentos contaminados pelos agrotóxicos e a regulamentação do comércio externo (MARQUES, NEVES e VENTURA, 2010; JARDIM, ANDRADE e QUEIROZ, 2009). A classificação dos produtos químicos em relação à toxicidade aguda se baseia na dose letal $50\left(\mathrm{DL}_{50}\right)$, que representa a dose capaz de matar $50 \%$ dos indivíduos da população em teste. Quanto menor a $\mathrm{DL}_{50}$, maior a toxicidade do produto. Além disso, a toxicidade crônica dos agrotóxicos pode ser avaliada mediante a Ingestão Diária Aceitável (IDA) (CARNEIRO et al., 2012). A IDA indica a quantidade do produto que pode ser ingerida diariamente, durante toda a vida do indivíduo, sem que haja riscos à sua saúde.

O MAPA criou o Plano Nacional de Controle de Resíduos e Contaminantes de Produtos de Origem Vegetal (PNCRC/Vegetal) em 2008, com o objetivo de inspecionar e fiscalizar a qualidade dos compostos produzidos em todo o território nacional em relação à ocorrência de resíduos de agrotóxicos e contaminantes químicos e biológicos, destinados ao mercado interno e à exportação. Cerca de $80 \%$ das análises do PNCRC/Vegetal tem sido realizadas para o mercado interno (BRASIL, 2009a).

\section{AGROTÓXICOS EM ALIMENTOS DE ORIGEM VEGETAL}

A crescente demanda por alimentos, acompanhada pelo aumento da área cultivada, propiciou maior utilização de agrotóxicos nos alimentos de origem vegetal para compensar os problemas do processo produtivo, principalmente relacionados à infestação de pragas (GAMA, OLIVEIRA e CAVALCANTE, 2013). Assim, os alimentos são considerados a principal fonte de exposição dos seres humanos aos agrotóxicos (GONZÁLEZ-RODRÍGUEZ et al., 2008; RIVAS et al., 2007).

Os agrotóxicos podem ser bioacumulados na cadeia alimentar, atuando sobre os sistemas biológicos vitais dos seres vivos, como o sistema nervoso (inibição da enzima acetilcolinesterase), o sistema respiratório e a inibição do transporte de elétrons nas mitocôndrias, tornando-se potencialmente tóxicos para os seres humanos (MATSADIQ et al., 2011).

Para minimizar a exposição humana aos resíduos de agrotóxicos presentes nos alimentos de origem vegetal e assegurar a saúde pública, agências reguladoras de vários países têm estabelecido LMR cada vez menores e criado programas de monitoramento de resíduos de agrotóxicos em alimentos (ŠKRBIC e PREDOJEVIC', 2008). Isso pode causar conflitos, pois níveis 
de resíduos aceitáveis em um país são inaceitáveis em outro. No Brasil, esses limites variam entre 0,01 e $10 \mathrm{mg} \mathrm{kg}^{-1}$, dependendo da espécie vegetal e do produto (BRASIL, 2012b).

Em 2010, o PARA monitorou os seguintes alimentos de origem vegetal: abacaxi, alface, arroz, batata, beterraba, cebola, cenoura, couve, feijão, laranja, maçã, mamão, manga, morango, pepino, pimentão, repolho e tomate. Todos foram selecionados de acordo com sua disponibilidade nos supermercados das 26 Unidades Federativas do Brasil, gerando o total de 2.488 amostras. De acordo com os resultados obtidos no monitoramento, $28 \%$ das amostras foram consideradas insatisfatórias por apresentarem resíduos de pesticidas não autorizados ou teores de resíduos acima do permitido pela legislação brasileira. Constataram-se agrotóxicos não autorizados para as culturas analisadas em $24,3 \%$ das amostras e a presença de resíduos em níveis acima dos LMR permitidos em 1,9\% do total das amostras (BRASIL, 2011b).

Os resultados encontrados por cultura analisada pelo PARA em 2009 foram semelhantes ao do PARA 2010, sendo que $29 \%$ das 3.130 amostras analisadas foram consideradas insatisfatórias. Em 2008, o percentual de irregularidades foi menor em relação aos anos de 2010 e 2009. Das 1.685 amostras avaliadas, $16 \%$ foram consideradas insatisfatórias (BRASIL 2010a, BRASIL, 2009b). Na Tabela 1 encontram-se os resultados insatisfatórios em relação aos LMR de alguns alimentos de origem vegetal entre os anos de 2008 e 2010.

\section{TABELA 1 - RESULTADOS INSATISFATÓRIOS (\%) DO PARA DE RESÍDUOS DE AGROTÓXICOS EM ALIMENTOS DE ORIGEM VEGETAL ENTRE OS ANOS DE 2008 E 2010}

\begin{tabular}{c|c|c|c}
\hline \multirow{2}{*}{ Alimentos } & \multicolumn{3}{|c}{ Ano } \\
\cline { 2 - 4 } & $\mathbf{2 0 0 8}$ & $\mathbf{2 0 0 9}$ & $\mathbf{2 0 1 0}$ \\
\hline Abacaxi & $9,47^{*}$ & 44,1 & 32,8 \\
\hline Alface & 19,80 & 38,4 & 54,2 \\
\hline Arroz & 4,41 & 27,2 & 0,4 \\
\hline Banana & 1,03 & 3,5 & $\mathrm{~N}$ \\
\hline Batata & 2,00 & 1,2 & 32,6 \\
\hline Beterraba & $\mathrm{N}^{* *}$ & 32,0 & 3,1 \\
\hline Cebola & 2,91 & 16,3 & 49,6 \\
\hline Cenoura & 30,39 & 24,8 & 31,9 \\
\hline Couve & $\mathrm{N}$ & 44,2 & 6,5 \\
\hline Feijão & 2,92 & 3,0 & 12,2 \\
\hline Laranja & 14,85 & 10,3 & 8,9 \\
\hline Maçã & 3,92 & 5,3 & 30,4 \\
\hline Mamão & 17,31 & 38,8 & 4,0 \\
\hline Manga & 0,99 & 8,1 & 63,4 \\
\hline Morango & 36,05 & 50,8 & 57,4 \\
\hline Pepino & $\mathrm{N}$ & 54,8 & 91,8 \\
\hline Pimentão & 64,36 & 80,0 & 6,3 \\
\hline Repolho & 8,82 & 20,5 & 16,3 \\
\hline Tomate & 18,27 & 32,6 & $\mathrm{~N}$ \\
\hline Uva & 32,67 & 56,4 & \\
\hline & & & \\
\hline & & & \\
\hline & & & \\
\hline
\end{tabular}

* = resultados expressos em percentagem (\%). ${ }^{* *} \mathrm{~N}$ = análises não realizadas. Fonte: BRASIL, 2011b; 2010a; $2009 \mathrm{~b}$. 
As irregularidades encontradas nos alimentos vegetais estão relacionadas, principalmente, ao uso indiscriminado de agrotóxicos não autorizados para as culturas (BRASIL, 2008).

As culturas que mais despertaram a atenção das agências reguladoras foram o pimentão e o morango. Entre 2008 a 2010, os resultados insatisfatórios dessas culturas aumentaram, aproximadamente em $27 \%$ do total das amostras. A contaminação ocorreu principalmente por produtos não autorizados para essas culturas, destacando-se o fungicida carbendazim do grupo químico benzimidazol. Esse fungicida também foi encontrado nas culturas de abacaxi, alface, beterraba, couve e repolho para as quais sua aplicação não é permitida legalmente. A aplicação desse fungicida é autorizada apenas nas culturas de grãos, citrus e maçã (BRASIL, 2012b).

Os inseticidas clorpirifós, metamidofós e acefato, pertencentes ao grupo químico dos organofosforados, também contribuíram para o aumento do número amostras insatisfatórias nas culturas analisadas, devido aplicação não autorizada e/ou detecção de teores de resíduos acima do permitido (BRASIL, 2011b). A ANVISA determinou por meio da RDC 01/2011, a proibição do uso do metamidofós no mercado nacional a partir do dia 30 de junho de 2012 pelo fato de seu ingrediente ativo apresentar características neurotóxicas, imunotóxicas e provocar toxicidade sobre o sistema endócrino e o desenvolvimento embriofetal (BRASIL, 2011a).

O tomate, no ano de 2007, apresentou irregularidades em 44,72 \% das amostras (BRASIL, 2008). Mesmo ocupando a $10^{\mathrm{a}}$ posição no último relatório do PARA, em razão da redução da quantidade de agrotóxicos, essa cultura ainda apresenta irregularidades (BRASIL, 2011b). De acordo com a ANVISA (Brasil, 2009b) foram encontrados vários resíduos de agrotóxicos não autorizados na cultura do tomate, tais como aldicarbe, aletrina, clorpirifós metílico, metamidofós, ciproconazol e folpete. $\mathrm{O}$ aldicarbe, inseticida do grupo químico metilcarbamato de oxima, tem sua venda restrita nos estados da Bahia, Minas Gerais e São Paulo por ser considerado o ingrediente ativo com a maior toxicidade aguda para mamíferos. Sua reavaliação torna-se necessária no contexto de uso irregular e indiscriminado como raticida e agente abortivo, bem como em tentativas de homicídio e suicídio, acarretando grave problema de saúde pública.

Resíduos de agrotóxicos dos grupos químicos dos organoclorados, organofosforados, carbamatos e piretroides foram monitorados na cidade de São Paulo em frutas e vegetais por Gebara et al. (2005). A pesquisa envolveu 2.223 amostras, sendo 700 vegetais e 1.523 frutas coletadas e analisadas para 100 resíduos de agrotóxicos. Em relação à amostragem geral, em 67,4 $\%$ das amostras foram detectados resíduos desses compostos. As amostras de frutas apresentaram maior teor de resíduos de agrotóxicos (34,2\%) que os vegetais $(29,0 \%)$ de forma semelhante ao observado por Baker et al. (2002). As amostras de frutas analisadas continham maior teor de resíduos de agrotóxicos em relação às amostras vegetais, com diferença de 17 \%. De acordo com Gebara et al. (2005), entre todas as hortaliças, os LMR foram superiores na cultura de vagem e tomate, e dentre as frutas nas culturas de pêssego e morango. Os produtos frequentemente encontrados foram captana, clorotalonil, endosulfan e procimidona, além de agrotóxicos banidos no Brasil desde 1985, como dieltrin, predominante na cultura de melão $(0,01 \mathrm{mg} \mathrm{kg})$ e hexaclorocicloexano $(\mathrm{HCH})$ dominante na cultura de morango $\left(0,09 \mathrm{mg} \mathrm{kg}^{-1}\right)$.

Os fungicidas do grupo ditiocarbamatos (DTC) figuram entre os agrotóxicos mais detectados na União Europeia e que ultrapassam com maior frequência os LMR, conforme o programa de monitoramento de resíduos de agrotóxicos em produtos de origem vegetal na União Europeia, desenvolvido em 2005 (EC, 2007).

Resíduos dos fungicidas mancozebe, manebe e propinebe, do grupo químico dos ditiocarbamatos, foram determinados em amostras de tomate, alface, pimentão, maçã, uva e morango procedentes das quatro províncias de Galícia (noroeste da Espanha). O pimentão foi o vegetal com mais amostras positivas (96,9\%) para resíduos de DCT, seguido pela tomate $(87,5 \%)$, alface $(71,9 \%)$, uva $(33,3 \%)$ e maçã $(15,6 \%)$ não sendo encontradas no morango. Além disso, $6 \%$ das amostras analisadas de alface e pimentão excederam os LMR (LÓPEZ-FERNÁNDEZ et al., 2012). No Brasil, não é permitida a aplicação do fungicida mancozeb na cultura de alface e o maneb 
está proibido em todas as culturas. O uso do fungicida propinebe não é permitido nas culturas de alface e morango (BRASIL, 2012b).

Resíduos de 16 organoclorados (OCP) foram investigados em 39 amostras de farinha de trigo, óleo de girassol, açúcar branco e subprodutos de beterraba adquiridos na província de Vojvodina, na Sérvia, entre 2002 e 2004. O inseticida 4,4-DDT (diclorodifeniltricloroetano) foi detectado com maior frequência $(76,9 \%$ ) em relação ao total das amostras analisadas, seguido pelo lindano $(66,7 \%), \beta-\mathrm{HCH}$ (beta-hexaclorocicloexano) $(48,7 \%)$, e endosulfan II (41,0\%) (ŠKRBIC e PREDOJEVIC', 2008). Segundo os autores, os resíduos de agrotóxicos determinados no estudo foram menores do que os respectivos LMR estabelecidos pela União Europeia nos anos de $2002 \mathrm{e}$ 2004.

Wang et al. (2013) avaliaram 33 agrotóxicos comumente utilizados em vegetais de área agrícola da China. Verificaram que o inseticida ometoato, do grupo químico dos organofosforados, foi o mais frequente nas amostras analisadas (concentrações médias de $0,3230 \mathrm{mg} \mathrm{kg}^{-1}$ ), principalmente nas culturas de pimentão verde, feijão, alho-poró e espinafre. A utilização do inseticida ometoato foi proibida na china a partir de 2007 e no Brasil desde 1985, porém ainda é encontrado de forma ilegal principalmente na cultura do abacaxi.

Sinha, Rao e Vasudey (2012) analisaram 18 agrotóxicos organofosforados em diferentes amostras de vegetais (berinjela, quiabo, couve-flor, repolho, tomate e pimentão) e verificaram que quase todas continham principalmente resíduos de clorpirifós, fosalona, acefato e triazofós. No Brasil, não é permitida a aplicação do inseticida fosalona em culturas agrícolas (BRASIL, 2012b). De acordo com os resultados de Sinha, Rao e Vasudey (2012), a cultura de quiabo apresentou as maiores irregularidades e a de pimentão as menores em relação aos produtos hortícolas analisados na cidade de Hyderab (Índia).

No estudo de Bakore, John e Bhatnagar (2004), amostras de grãos de trigo obtidas na cidade de Jaipur, na Índia, apresentaram altos teores de resíduos de agrotóxicos do grupo dos organoclorados acima dos LMR permitidos: até $36 \mu \mathrm{g} \mathrm{g}^{-1}$ de heptacloro; $10 \mu \mathrm{g} \mathrm{g}^{-1}$ de $\beta$ - $\mathrm{HCH}$; $8 \mu \mathrm{g} \mathrm{g}^{-1}$ para $\mathrm{y}-\mathrm{HCH} ; 6 \mu \mathrm{g} \mathrm{g}^{-1}$ para heptacloro epóxido; $2 \mu \mathrm{g} \mathrm{g}^{-1}$ para aldrin; 0,8 $\mu \mathrm{g} \mathrm{g}^{-1}$ para 4,40-DDD (Diclorodifenildicloroetano); e 0,3 $\mu \mathrm{g} \mathrm{g}^{-1}$ para 4,40-DDE (Dicloroetileno). Segundo os autores, os elevados teores de resíduos decorre da grande utilização desses produtos durante o armazenamento de grãos, prática comum na Índia, devido ao baixo custo e versatilidade contra várias pragas de grãos armazenados. No estudo realizado na cidade de Lucknow (Índia) não foi detectada a presença dos agrotóxicos organoclorados aldrin e DDT em 20 amostras de produtos hortícolas (SRIVASTAVA et al., 2011).

Os ingredientes ativos do grupo químico dos organoclorados, aldrin, DDT, $\mathrm{HCH}$ e heptacloro foram proibidos no Brasil para uso agropecuário em 1985 (BRASIL, 1985). O endosulfan está em fase de descontinuidade de comercialização e uso até o cancelamento de sua monografia, previsto para o dia 31 de julho de 2013 (BRASIL, 2010b). Esse composto é muito aplicado nas culturas de soja, algodão, café, cacau e cana-de-açúcar (SILVA, LOURENCETTI e DORES, 2010; GEBARA et al., 2005) e utilizado de forma ilegal e indiscriminada, principalmente nas culturas de pepino e pimentão (BRASIL, 2011b; 2010a). A proibição dos organoclorados fundamenta-se na persistência dos ingredientes ativos e/ou dos seus metabólitos no ambiente e sua grande capacidade de dispersão e de acúmulo em tecidos gordurosos, o que os tornam bioacumulativos na cadeia alimentar, além de apresentarem grande estabilidade físico-química (ALMEIDA et al., 2007).

Amoah et al. (2006) avaliaram 180 amostras de vegetais folhosos (alface, repolho e cebolinha) em supermercados de três grandes cidades de Gana (África), Accra, Kumasi e Tamale. Os resíduos dos agrotóxicos avaliados excederam os LMR permitidos para as culturas, com predominância do inseticida organofosforado clorpirifós amplamente utilizado por produtores de hortaliças em Gana. Segundo Wang et al. (2013) tornou-se comum encontrar maior concentração de resíduos de organofosforados em vegetais folhosos pelo fato dessas culturas serem mais propensas ao ataque de insetos. 
Khouri (2007) analisou a ocorrência dos herbicidas atrazina e simazina em amostras de cultura convencional e orgânica de abacaxi no estado de Goiás. As amostras consideradas do grupo orgânico apresentaram resíduos de atrazina e simazina com valores superiores ao permitido pela legislação $\left(0,02 \mathrm{mg} \mathrm{kg}^{-1}\right)$. Os abacaxis cultivados em sistema convencional não apresentaram resíduo desses agrotóxicos, o que pode indicar que as exigências de controle de qualidade nesses sistemas estão sendo seguidas com mais rigor, enquanto nos abacaxis ditos orgânicos parece faltar inspeção por parte dos órgãos competentes.

Baker et al. (2002) analisaram resíduos de agrotóxicos em alimentos de origem vegetal cultivados por meio dos sistemas convencional, produção integrada e orgânico nos Estados Unidos daAmérica e verificaram a presença de resíduos nos alimentos cultivados pelos três sistemas, mas as maiores quantidades de resíduos foram detectadas nas amostras procedentes do sistema convencional (73 \%). As amostras de salsão, pêra, maçã, pêssego e morango mostraram os maiores teores de resíduos em aproximadamente $90 \%$ das amostras analisadas. A presença de múltiplos resíduos de agrotóxicos foi observada em $46 \%$ das amostras do cultivo convencional, $24 \%$ do sistema integrado e $7 \%$ do cultivo orgânico, sugerindo que esse último não pode ser considerado alimento orgânico. A presença de múltiplos resíduos de agrotóxicos em sistema orgânico pode ser devido ao fato do solo de produção ainda apresentar contaminação ambiental (produtos persistentes) ou as barreiras vegetais não foram suficientes para evitar a passagem de produtos químicos provenientes do sistema convencional.

A degradação dos resíduos de agrotóxicos presentes nos alimentos ocorre por mecanismos oxidativos. Em alimentos ricos em compostos antioxidantes, como o tomate, pimentão, citrus e seus sucos, a oxidação pode ser mais lenta, aumentando a persistência dos resíduos desses compostos (PICÓ e KOZMUTZA, 2007).

Os produtos de degradação dos agrotóxicos podem ser mais tóxicos que o composto original. O inseticida organofosforado parationa, por exemplo, sofre biotransformação quando absorvido, formando metabólito ativo (denominado paraoxona) por meio da oxidação das ligações tiofosfato $(P=S)$ a ortofosfato $(P=O)$. Sob essa forma, os organofosforados aumentam e prolongam os efeitos de inibição da enzima acetilcolinesterase do principio ativo (BRASIL, 2012a).

Operações como a lavagem e o descasque podem não contribuir totalmente para a redução da ingestão de resíduos de agrotóxicos contidos nos alimentos. A lavagem auxilia a redução de resíduos presentes na superfície dos vegetais, principalmente dos produto polares. Como exemplo tem-se o inseticida carbaril, do grupo químico metilcarbamato de naftila, comumente aplicado nas culturas de abacaxi, alho, banana, batata, feijão, maçã e tomate. Os produtos apolares tendem a permanecer nas camadas lipofílicas de frutos e vegetais. Os agrotóxicos quando aplicados diretamente nas plantações mostram difusão limitada à cutícula, sendo passíveis de remoção mediante descasque (KAUSHIK, SATYA e NAIK, 2009).

As Boas Práticas Agrícolas (BPA) são pré-requisitos importantes na produção de alimentos vegetais de qualidade, possibilitando decisões regulatórias comerciais a fim de garantir a segurança alimentar e a utilização racional e cuidadosa dos agrotóxicos (CRUZ, CENCI e MAIA, 2006).

\section{CONCLUSÃO}

Os agrotóxicos têm sido amplamente utilizados na agricultura para assegurar alta produtividade pela redução de perdas de culturas e garantir a qualidade dos produtos. No entanto, agrotóxicos quando usados de forma inadequada são responsáveis por graves consequências aos seres humanos, tanto aos que lidam diretamente com o produto, quanto à população em geral mediante ingestão de alimentos de origem vegetal.

Os padrões e regulamentos buscam garantir o uso seguro dos agrotóxicos, mas seus objetivos não podem ser alcançados sem a efetiva implementação de monitoramento periódico e consciente. Isso exige instalações apropriadas, profissionais capacitados e legislação devidamente estruturada. 
A utilização das BPA, a certificação e a punição com multas podem contribuir para a diminuição da exposição do consumidor e do aplicador à essas substâncias tóxicas, responsáveis por sérias doenças, bem como minimizar seus efeitos adversos ao ecossistema.

\section{ABSTRACT \\ PESTICIDE RESIDUES IN PLANT ORIGIN FOOD: REVIEW}

This literature review presents discussions found in researches on pesticides residue in vegetal food focusing the determination of Maximum Residue Limits (MRL) of these products in fruits and vegetables. Were also addressed the Pesticides residue in food Analysis Program (Programa de Análise de Resíduos de Agrotóxicos em Alimentos (PARA)) and The National Plan of Residue and contaminants on plat origin foods (PNCRC/ Vegetal - BRAZIL) created by the Ministry of Agriculture, Lifestock and Supply (MAPA - Brazil). It was concluded that the safe use of pesticides, which is the actual aim of standards and regulations, will only be achieved through effective monitoring. The application of Good Agricultural Practices (GAP), certification and punishment bill may contribute to reduce consumers' exposure to toxic substances responsible for serious diseases as well as minimize side effects to the environment.

KEY-WORDS: FRUITS AND VEGETABLES, MONITORING, MAXIMUM RESIDUE LIMITS.

\section{REFERÊNCIAS}

1 ALMEIDA, F.V.; CENTENO, A.J.; BISINOTI, M.C.; JARDIM, W.F. Substâncias tóxicas persistentes (STP) no Brasil. Química Nova, v.30, n.8, p.1976-1985, 2007.

2 AMOAH, P.; DRECHSEL, P.; ABAIDOO, R.C.; NTOW, W.J. Pesticide and pathogen contamination of vegetables in Ghana's urban markets. Archives of Environmental Contamination and Toxicology, v.50, n.1, p.1-6, 2006.

3 BAI, Y.; ZHOU, L.; WANG, J. Organophosphorus pesticide residues in market foods in Shaanxi area, China. Food Chemistry, v.98, n.2, p.240-242, 2006.

4 BAKER, B.P.; BENBROOK, C.M.; GROTH, E.; BENBROOK, K.L. Pesticide residues in conventional, integrated pest management (IPM) - grown and organic foods: insights from three US data sets. Food Additives and Contaminants, v.19, n.5, p.427-446, 2002.

5 BAKIRCI, G.T.; HIŞIL, Y. Fast and simple extraction of pesticide residues in selected fruits and vegetables using tetrafluoroethane and toluene followed by ultrahigh-performance liquid chromatography/tandem mass spectrometry. Food Chemistry, v.135, n.3, p.1901-1913, 2012.

6 BAKORE, N.; JOHN, P.J.; BHATNAGAR, P. Organochlorine pesticide residues in wheat and drinking water samples from Jaipur, Rajasthan, India. Environmental Monitoring and Assessment, v.98, n.1-3, p.381-389, 2004.

7 BOTITSI, H.; ECONOMOU, A.; TSIPI, D. Development and validation of a multi-residue method for the determination of pesticides in processed fruits and vegetables using liquid chromatography-electrospray ionization tandem mass spectrometry. Analytical and Bioanalytical Chemistry, v.389, n.6, p.1685-1695, 2007.

8 BRASIL. Ministério da Agricultura. Portaria n. 329, de 2 de setembro de 1985. Proibe em todo território nacional a comercialização, o uso e a distribuição dos produtos agrotóxicos organoclorados destinados a agropecuária dentre outros Diário Oficial [da] República Federativa do Brasil, 3 de setembro de 1985.

9 BRASIL. Agência Nacional de Vigilância Sanitária (ANVISA). Programa de Análise de Resíduos de Agrotóxicos em Alimentos (PARA). Relatório de atividades de 2001 - 2007. Brasília, 2008. 21 p.

10 BRASIL. Ministério da Agricultura, Pecuária e Abastecimento (MAPA). Instrução Normativa n. 42, de 31 de dezembro de 2008. Institui o Plano nacional de controle de resíduos e contaminantes em produtos de origem vegetal (PNCRC/ Vegetal). Brasília, 2009.

11 BRASIL. Agência Nacional de Vigilância Sanitária (ANVISA). Programa de análise de resíduos de agrotóxicos em alimentos (PARA). Nota Técnica para divulgação dos resultados do PARA de 2008. Brasília, 2009. 12 p.

12 BRASIL. Agência Nacional de Vigilância Sanitária (ANVISA). Programa de análise de resíduos de agrotóxicos em alimentos (PARA). Relatório de atividades de 2009. Brasília, 2010. 22 p.

13 BRASIL. Agência Nacional de Vigilância Sanitária (ANVISA). RDC n. 28, de 09 de agosto de 2010. Regulamento técnico para o ingrediente ativo endossulfam em decorrência da reavaliação toxicológica. Brasília, 2011.

14 BRASIL. Agência Nacional de Vigilância Sanitária (ANVISA). RDC n. 1, de 14 de janeiro de 2011. Regulamento técnico 
para o ingrediente ativo metamidofós em decorrência da reavaliação toxicológica. Brasília, 2011.

15 BRASIL. Agência Nacional de Vigilância Sanitária (ANVISA). Programa de análise de resíduos de agrotóxicos em alimentos (PARA). Relatório de atividades de 2010. Brasília, 2011. 26 p.

16 BRASIL. Agência Nacional de Vigilância Sanitária (ANVISA). Consulta pública n. 8, de 19 de janeiro de 2012. Proposta de regulamento técnico para o ingrediente ativo parationa metílica em decorrência da reavaliação toxicológica. Brasília, 2012.

17 BRASIL. Ministério da Agricultura, Pecuária e Abastecimento (MAPA). Instrução Normativa n. 27, de 11 de dezembro de 2012. Tabela de agrotóxicos monitorados e limites máximos de resíduos. Brasília, 2012.

18 CARNEIRO, F.F.; PIGNATI, W.; RIGOTTO, R.M.; AUGUSTO, L.G.S.; RIZOLLO, A.; MULLER, N.M.; ALEXANDRE, V.P.; FRIEDRICH, K.; MELLO, M.S.C. Dossiê ABRASCO: um alerta sobre os impactos dos agrotóxicos na saúde. Rio de Janeiro: ABRASCO, 2012. 98 p. Parte 1.

19 COOPER, J.; DOBSON, H. The benefits of pesticides to mankind and the environment. Crop Protection, v.26, n.9, p.1337-1348, 2007.

20 CRUZ, A.G.; CENCI, S.A.; MAIA, M. C. A. Good agricultural practices in a Brazilian produce plant. Food Control, v.17, n.10, p.781-788, 2006

21 European Commission (EC). Monitoring of pesticide residues in products of plant origin in the European Union, Norway, Iceland and Lichtenstein, 2005. Brussels, Belgium, 2007.

22 EL-SHAHAWI, M.S.; HAMZA, A.; BASHAMMAKH, A.S.; AL-SAGGAF, W.T. An overview on the accumulation, distribution, transformations, toxicity and analytical methods for the monitoring of persistent organic pollutants. Talanta, v.80, n.5, p.1587-1597, 2010.

23 GALLI, A.; SOUZA, D.; GARBELLINI, G.S.; COUTINHO, C.F.B.; MAZO, L.H.; AVACA, L.A.; MACHADO, S.A.S. Utilização de técnicas eletroanalíticas na determinação de pesticidas em alimentos. Química Nova, v.29, n.1, p.105-112, 2006.

24 GAMA, A.F.; OLIVEIRA, A.H.B.; CAVALCANTE, R.M. Inventário de agrotóxicos e risco de contaminação química dos recursos hídricos no semiárido cearense. Química Nova, v.36, n.3, p.462-467, 2013.

25 GEBARA, A.B.; CISCATO, C.H.P.; FERREIRA, M.S.; MONTEIRO, S.H. Pesticide residues in vegetables and fruits monitored in São Paulo city, Brazil, 1994-2001. Bulletin of Environmental Contamination and Toxicology, v.75, n.1, p.163-169, 2005

26 GONZÁLEZ-RODRÍGUEZ, R.M.; RIAL-OTERO, R.; CANCHO-GRANDE, B.; SIMAL-GÁNDARA, J. Occurrence of fungicide and insecticide residues in trade samples of leafy vegetables. Food Chemistry, v.107, n.3, p.1342-1347, 2008.

27 GONZÁLEZ-RODRÍGUEZ, R.M.; CANCHO-GRANDE, B.; SIMAL-GÁNDARA, J. Decay of fungicide residues during vinification of white grapes harvested after the application of some new active substances against downy mildew. Food Chemistry, v.125, n.2, p.549-560, 2011.

28 JARDIM, I.C.S.F.; ANDRADE, J.A.; QUEIROZ, S.C.N. Resíduos de agrotóxicos em alimentos: uma preocupação ambiental global - um enfoque às maçãs. Química Nova, v.32, n.4, p.996-1012, 2009.

29 KAUSHIK, G.; SATYA, S.; NAIK, S.N. Food processing a tool to pesticide residue dissipation - a review. Food Research International, v.42, n.1, p.26-40, 2009.

30 KHALILI-ZANJANI, M.R.; YAMINI, Y.; YAZDANFAR, N.; SHARIATI, S. Extraction and determination of organophosphorus pesticides in water samples by a new liquid phase microextraction-gas chromatography-flame photometric detection. Analytica Chimica Acta, v.606, n.2, p.202-208, 2008.

31 KHOURI, A.G. Análise de resíduos de atrazina e simazina em abacaxi no estado de Goiás. 2007. 72 p. Dissertação (Mestrado em Ecologia e Produção Sustentável) - Universidade Católica de Goiás, Goiânia, 2007.

32 LÓPEZ-FERNÁNDEZ, O.; RIAL-OTERO, R.; GONZÁLEZ-BARREIRO, C.; SIMAL-GÁNDARA, J. Surveillance of fungicidal dithiocarbamate residues in fruits and vegetables. Food Chemistry, v.134, n.1, p.366-374, 2012.

33 MARQUES, C.R.G.; NEVES, P.M.O.J.; VENTURA, M.U. Diagnóstico do conhecimento de informações básicas para o uso de agrotóxicos por produtores de hortaliças da Região de Londrina. Semina: Ciências Agrárias, v.31, n.3, p.547$556,2010$.

34 MATSADIQ, G.; HU, H.; REN, H.; ZHOU, Y.; LIU, L.; CHEN, J. Quantification of multi-residue levels in peach juices, pulps and peels using dispersive liquid-liquid microextraction based on floating organic droplet coupled with gas chromatography-electron capture detection. Journal of Chromatography B, v.879, n.22, p.2113-2118, 2011.

35 PICÓ, Y.; KOZMUTZA, C. Evaluation of pesticide residue in grape juices and the effect of natural antioxidants on their 
degradation rate. Analytical and Bioanalytical Chemistry, v.389, n.6, p.1805-1814, 2007.

36 RICE, P.J.; RICE, M.P.; ARTHUR, E.L.; BAREFOOT, A.C. Advances in pesticide environmental fate and exposure assessments. Journal of Agricultural and Food Chemistry, v.55, n.14, p.5367-5367, 2007.

37 RIVAS, A.; CERRILLO, I.; GRANADA, A.; MARISCAL-ARCAS, M.; OLEA-SERRANO, F. Pesticide exposure of two age groups of women and its relationship with their diet. Science of the Total Environment, v.382, n.1, p.14-21, 2007.

38 SHARMA, D.; NAQPAL, A.; PAKADE, Y.B.; KATNORIA, J.K. Analytical methods for estimation of organophosphorus pesticide residues in fruits and vegetables: a review. Talanta, v.82, n.4, p.1077-1089, 2010.

39 SILVA, F.A.; LOURENCETTI, C.; DORES, E.F.G.C. Influência da temperatura, umidade e profundidade do solo na persistência do diurom e sulfato de endossulfam em um solo tropical. Química Nova, v.33, n.7, p.1457-1463, 2010.

40 SINHA, S.N.; RAO, M.V.V.; VASUDEY, K. Distribution of pesticides in different commonly used vegetables from Hyderabad, India. Food Research International, v.45, n.1, p.161-169, 2012.

41 ŠKRBIC, B.; PREDOJEVIC', Z. Levels of organochlorine pesticides in crops and related products from Vojvodina, Serbia: estimated dietary intake. Archives of Environmental Contamination and Toxicology, v.54, n.4, p.628-636, 2008.

42 SRIVASTAVA, A.K.; TRIVEDI, P.; SRIVASTAVA, M.K.; LOHANI, M.; SRIVASTAVA, L.P. Monitoring of pesticide residues in market basket samples of vegetable from Lucknow City, India: Quechers method. Environmental Monitoring and Assessment, v.176, n.1-4, p.465-472, 2011.

43 WANG, S.; WANG, Z.; ZHANG, Y.; WANG, J.; GUO, R. Pesticide residues in market foods in Shaanxi Province of China in 2010. Food Chemistry, v.138, n.2-3, p.2016-2025, 2013. 